\title{
Translinguismos e a visão heteroglóssica de linguagem em práticas comunicativas no Facebook
}

\author{
Diogo Oliveira do Espírito Santo (PPGLINC/UFBA)* \\ https://orcid.org/0000-0003-4805-4430
}

\section{Resumo:}

Neste artigo, serão exploradas as contribuições da perspectiva heteroglóssica bakhtiana atrelada à noção de translinguismo, como alternativas para o estudo de práticas de linguagem em que sujeitos mobilizam variados recursos linguístico-semióticos no Facebook. Para isso, dados gerados de uma pesquisa de doutorado serão discutidos com base nos princípios da abordagem netnográfica e nos pressupostos do paradigma transglóssico. Com essa discussão, espera-se dar atenção à percepção de que as maneiras através das quais o uso de formas linguísticas, seja dentro ou além do que tipicamente chamamos de "línguas", está relacionado a posições identitárias e ideológicas específicas, demandando, assim, novas perspectivas de estudo sobre a linguagem online que acentuem seu caráter fluido, híbrido e multifacetado.

Palavras-chave: Heteroglossia. Translinguismo. Transglossia. Facebook.

\section{Abstract:}

\section{Translingualism and the heteroglossic view of language in communicative practices on Facebook}

In this article, some contributions of the Bakhtinian perspective on language linked to the notion of translanguaging will be explored, as an alternative to the study of language practices in which subjects mobilize a range of linguistic-semiotic resources on their Facebook posts. Drawing on the tenets of the netnographic approach and the transglossic framework, data collected from a doctorate research will be discussed. This study aims to highlight the notion that the ways through which linguistic forms, whether within or beyond what we call "languages", point to specific identity and ideological positions, which demands new perspectives on language studies that focus on its fluid, hybrid and multifaceted nature.

Keywords: Heteroglossia. Translingualism. Transglossia. Facebook.

* Professor assistente de Língua Inglesa do Centro de Formação de Professores da Universidade Federal do Recôncavo da Bahia (CFP/UFRB). Mestre e doutorando em Linguística Aplicada pelo Programa de Língua e Cultura da Universidade Federal da Bahia (PPGLINC/UFBA). Líder do Grupo de Pesquisa do CNPq em Estudos de Língua Inglesa do Centro de Formação de Professores (GPELI-UFRB). E-mail: diogo_oliveira.ufba@outlook.com 


\section{Introdução}

Dispositivos móveis como smartphones e tablets e sites de redes sociais como o Youtube e Facebook têm ganhado mais espaço no nosso dia a dia, desempenhando papel importante nas práticas de linguagem on e offline. Tais recursos impulsionaram o desenvolvimento de formas híbridas de comunicação, uma vez que sujeitos de contextos étnico-culturais diversos interagem uns com os outros através da imbricação de diferentes recursos linguísticos e semióticos, colocando em xeque as fronteiras ora impostas às línguas por perspectivas modernas e coloniais nos estudos da linguagem (MAKONI; PENNYCOOK; 2007).

A combinação de línguas, repertórios, modos, estilos e gêneros na comunicação mediada pela tecnologia tem levado, então, pesquisadores a considerar a diversidade linguística e semiótica como ponto de partida para se estudar as práticas de linguagem na contemporaneidade. Com isso, o foco predominante nesses estudos tem sido dado a perspectivas que compreendem os processos comunicativos como uma forma de prática social (BARTON; LEE, 2015).

Corroborando essa concepção de comunicação mediada pela tecnologia digital, neste artigo, eu me apoio na noção de heteroglossia de Mikhail Bakhtin (1981) e das recentes perspectivas "trans" de linguagem, quais sejam a do translinguismo/translinguagem (CANAGARAJAH, 2013; GARCÍA; WEI, 2014), para discutir interações no Facebook de sujeitos comumente caracterizados como bi/multilíngues. Partindo da premissa de que tais práticas envolvem complexas camadas de construção de sentido, esses pressupostos teóricos serão mobilizados a fim de problematizar a inadequação de termos como codeswitching na análise das práticas de linguagem em que recursos linguísticos e culturais são negociados, impostos e resistidos pelos sujeitos (CANAGARAJAH; DOVCHIN, 2019).

Para esse debate, eu analiso dados gerados em uma pesquisa de doutorado ${ }^{1}$, em que problematizo os processos de construção de sentido em um post de Facebook publicado por um sujeito bi/multilíngue. Para tal fim, faço considerações sobre as noções de heteroglossia e translinguagem, na tentativa de expandir orientações teóricas engajadas na elucidação da diversidade linguística na Internet, e pontuo as implicações dessas posturas para a compreensão da natureza social, política e histórica da linguagem em contextos mediados pela tecnologia digital. Em seguida, apresento o percurso metodológico da pesquisa, com ênfase na netnografia (KOZINETS, 2010), uma abordagem etnográfica de estudos de práticas de linguagem mediadas pela tecnologia digital conduzida, exclusivamente, através de meios e instrumentos de geração de dados online. Por fim, faço uma breve análise do post a partir dos pressupostos da heteroglossia e das perspectivas "trans" da linguagem (PENNYCOOK, 2007).

\section{Translinguagem ou codeswitching?}

Pesquisas recentes sobre o bi/multilinguismo em áreas da Sociolinguística e da Linguística Aplicada (doravante LA) têm se afastado da noção de língua como entidade homogênea, separada dos usos sociais dos sujeitos, e passado a considerar a comunicação como marcada pela mistura

1 A pesquisa, ainda em andamento, foi aprovada pelo Comitê de Ética da Universidade Federal da Bahia, sob parecer de número 3.168.263. 
de recursos linguístico-semióticos empregados como forma de cumprir propósitos comunicativos locais. Esses estudos advogam que conceitos como os de mono/bi/ multilinguismo têm falhado na consideração dos impactos da globalização no uso da linguagem e nos processos de construção identitária. Como alternativa, pesquisadores interessados em descrever e analisar as formas em que os sentidos são construídos através da linguagem têm preferido usar termos como: bilinguajamento (MIGNOLO, 2000); bilinguismo flexível (CREESE; BLACKLEDGE, 2010); metrolinguismo (OTSUJI; PENNYCOOK, 2015); práticas translíngues (CANAGARAJAH, 2013), translinguismo/translinguagem (GARCÍA, 2009; GARCÍA; WEI, 2014), translinguajar ${ }^{2}$ (LUCENA; HALL, 2019), entre outros.

Esses autores compartilham o entendimento de que o processo de construção de sentido não está atrelado ao uso de "línguas", compreendidas como um conjunto finito, discreto e enumerável de recursos linguísticos. Pelo contrário, tem-se defendido que diferentes semioses estão disponíveis em repertórios comunicativos (GUMPERZ; HYMES, 1972) ou semióticos espaciais (OTSUJI; PENNYCOOK, 2015), que se estendem por entre e para além das "línguas" e "variedades" que, ao longo dos anos, têm sido associadas a grupos nacionais, territoriais e sociais específicos. Essa perspectiva se afasta, assim, da longa tradição de se estudar as práticas de linguagem de sujeitos bi/ multilíngues através da concepção de codeswitching.

A discussão sobre codeswitching é ampla na Linguística e áreas afins. Com fre-

2 Salvaguardadas as diferenças contextuais de produção científica desses autores, todos esses termos serão tratados como sinônimos, já que se fundamentam em posturas epistemológicas semelhantes. quência, ele é tratado como um fenômeno da fala bi/multilíngue que engloba o uso de mais de uma língua no curso de um único episódio comunicativo (HELLER, 1988), como a alternância no uso de uma ou mais línguas (AUER, 1984), ou ainda como o uso de duas ou mais línguas numa mesma conversa (MYERS-SCOTTON, 1993). Apesar de distintas, tais percepções coadunam com a ideia de as línguas (códigos) "alternadas" ocupam "lugares" específicos na mente dos sujeitos (WEINREICH, 1968). No lado oposto dessa percepção, posturas alinhadas ao construto do translinguismo têm se deslocado da observação da alternância linguística, para o interesse de se investigar como os sujeitos manipulam seus repertórios a fim de atingirem seus propósitos sociais.

0 conceito translinguismo difere do de codeswitching por aquele se referir não simplesmente a uma mera mudança entre dois códigos, mas à construção e ao uso de práticas discursivas interrelacionadas que não podem ser associadas a uma ou outra definição mais estrutural de língua. Ele, portanto, se distancia do codeswitching no nível ontológico. Enquanto o codeswitching se embasa na visão monoglóssica de que os bi/multilíngues teriam dois sistemas linguísticos diferentes, a translinguagem postula que esse comportamento linguístico é heteroglóssico, ou seja, sempre dinâmico, como um sistema linguístico integrado. Daí a preferência pelo termo repertório em detrimento do de "línguas diferentes".

O que se pode perceber é que a prática da translinguagem é vista como uma mudança de voz, em que são mobilizados recursos de um amplo repertório de práticas linguísticas e sociais. De acordo com o linguista aplicado srilankês, Canagarajah (2004), a "voz" é a manifestação da agentividade dos sujei- 
tos no discurso em contextos microssociais de comunicação. Para o autor, é através dela que os sujeitos conseguem negociar, impor e resistir posicionamentos identitários através da linguagem. Dessa forma, Canagarajah (2004), bem como outros pesquisadores que trabalham sob a égide translíngue, ao enfatizar a importância das vozes nas problematizações sobre as práticas comunicativas, corroboram e ampliam a noção heteroglóssica de linguagem como postulada por Mikhail Bakhtin (1981), sobre a qual eu trato a seguir.

\section{A visão hetero/transglóssica de linguagem}

Heteroglossia $^{3}$ ou heterodiscurso é a tradução do termo russo raznorechie usado pelo filósofo da linguagem, Mikhail Bakhtin (1981). O conceito refere-se, em linhas gerais, aos usos simultâneos de diferentes formas de signos, às tensões e conflitos que existem entre eles e às associações sócio históricas que carregam (BAILEY, 2012). Apesar de Bakhtin (1981) tê-lo desenvolvido para análise do discurso no romance, sua reflexão apresenta uma outra perspectiva sobre a natureza da linguagem, que na contramão das ideias Saussurianas de langue e parole, enfatiza o caráter social e histórico das línguas.

Bakhtin argumenta que a língua em uso e ação representa "[...] pontos de vista específicos sobre o mundo, formas de conceituar o mundo em palavras, específicas visões do mundo, cada uma caracterizada pelos seus

3 Heteroglossia é o termo usado na versão norte-americana de $O$ discurso no romance (1981). Em nova tradução do texto, Bezerra (2015) opta pelo uso do termo heterodiscurso. Neste trabalho, ambos os termos serão usados como sinônimos, com preferência pelo primeiro devido a sua tradição na literatura. próprios objetos, sentidos e valores" ${ }^{4}$ (BAKHTIN, 1981, p. 291). Logo, a heteroglossia está relacionada à compreensão de como a linguagem é moldada pelos contextos sociais, históricos e políticos dos sujeitos. Assim, esse construto bem como o do translinguismo não tratam a língua como um código separado das práticas comunicativas dos sujeitos.

Para Bakhtin, a heteroglossia é marcada principalmente pela indexicalidade, tensão e multivocalidade. A indexicalidade enfatiza e identifica classes de pontos de vista, ideologias e outras posições sociais no uso da linguagem. Nesses termos, a estratificação linguística, por exemplo, derivaria não apenas de sua associação histórica, mas também de suas associações acompanhadas das avaliações que os usos linguísticos recebem em determinada cultura. Nesse sentido, diferentes formas linguísticas associadas a diferentes posições ideológicas são estratificadas em dialetos, gírias, línguas crioulas, pidgin e outras; sendo cada uma dessas posições valorizadas ou desvalorizadas a depender do contexto.

Dessa forma, entende-se que o uso da língua "indexa" um determinado ponto de vista, assim como é resultado de sua natureza social, refletindo as diferenças ideológicas que competem em uma determinada sociedade. Portanto, a heteroglossia diz respeito a muito mais do que o uso simultâneo de "línguas", visto que se refere à coexistência de diferentes perspectivas ideológicas, sejam elas constituídas em uma única "língua" nacional, sejam dentro de repertórios comunicativos complexos, como é o retrato das sociedades contemporâneas.

No entanto, essas formas indexicais

4 Todas as traduções de textos em língua estrangeira são de minha responsabilidade. 
não podem ser interpretadas sem levar em consideração as tensões sociais empregadas e construídas por elas, por isso Bailey (2012) acentua que umas das contribuições do construto da heteroglossia não é tanto sua referência às diferentes formas dos signos linguísticos, mas sim ao seu foco nas tensões sociais inerentes a qualquer língua.

Essas tensões aparecem na obra bakhtiniana como forças centrípetas e centrífugas. As forças centrípetas incluem as forças políticas, sociais e institucionais que tentam impor uma variedade de língua sobre as outras. Elas são assim chamadas porque tentam forçar os sujeitos a adotarem uma forma linguística unificadora e homogênea. As forças centrífugas, ao contrário, afastam os sujeitos de um centro comum e os levam em direção à diversidade, à heteroglossia. Apesar de distintas, o autor sugere que ambas as forças estão em competição no uso da linguagem, não existindo uma sem a outra. Outro construto usado na discussão sobre práticas heteroglóssicas é o da multivocalidade.

Para Bakhtin (1981), a palavra em uma língua é, em parte, a palavra de outra pessoa. Isso aponta para o fato de que a palavra tem sempre dois lados, já que no momento de seu uso, responde ao que a precede e antecipa o que está por vir. Assim, todas as formas linguísticas têm uma história e um futuro antecipado. Para Blackledge e Creese (2014, p. 10),

[...] Bakhtin observou que o que mais falamos são palavras dos outros, tanto que nossa fala transborda palavras de outras pessoas. Fazendo isso, nós ponderamos, avaliamos, refutamos, repudiamos, celebramos, afirmamos e assim por diante, não apenas palavras de outros, mas também as posições político-ideológicas representadas por tais palavras [...].
Segundo Bakhtin, portanto, todas as formas linguísticas são inerentemente dialógicas. Elas têm, ao mesmo tempo, uma história e um presente negociados durante a interação. Assim, os sujeitos não simplesmente povoam recursos linguísticos de acordo com suas intenções e histórias, para além disso, novas formas linguísticas são acrescidas àquelas já existentes, mesmo que de forma inconsciente. Dessa maneira, toda forma linguística é multivocal, isto é, reflete não apenas os nossos usos, como também o diálogo implícito entre vozes, intenções e histórias do passado e do presente.

A despeito do arcabouço heteroglóssico servir de base para se problematizar as vozes, tensões e a própria natureza da linguagem, acredito que ele não possa ser transplantado para interpretar todo tipo de uso da linguagem na contemporaneidade, devido as suas circunstâncias temporais e sociais, principalmente com os impactos das redes sociais em contextos contemporâneos. Por conta disso, é importante pontuar que neste artigo, eu tomarei a heteroglossia como pontapé inicial para a interpretação das práticas translíngues, mas, acrescentarei a ela perspectivas outras que se mostram adequadas para a reflexão dos desafios de se falar sobre a linguagem nos tempos atuais, como é o caso do paradigma transglóssico.

\section{Por uma noção transglóssica das práticas translíngues}

Como citei, anteriormente, pesquisas recentes em áreas da Sociolinguística e da LA têm buscado problematizar as noções de bi/multilinguismo apoiadas na consideração de que os termos apresentam lacunas na problematização do papel da diversidade dos re- 
cursos linguístico-semióticos que compõem os repertórios dos sujeitos. Por isso, uma gama de perspectivas que buscam capturar a complexidade das práticas de linguagem atuais tem reiterado, de maneiras diversas, os postulados de Bakhtin (1981). Indo além da mera reprodução dos estudos bakhtinianos, García e Wei (2014), Sultana, Dovchin e Pennycook (2018), por exemplo, vêm apostando na interação entre a perspectiva heteroglóssica com orientações transgressivas da linguagem (PENNYCOOK, 2007).

Tanto a heteroglossia como as orientações transgressivas tratam as línguas não como códigos separados entre si, mas sim como uma forma de translinguística (BAKHTIN, 1986), ou seja, uma forma de abordar a língua/linguagem para além dos seus aspectos formais e sistemáticos. Nesse contexto, tem sido dado preferência ao uso do termo transglossia, ou seja, o foco nas línguas já misturadas, não em termos de codeswitching, mas sim de recursos semióticos empregados no processo de construção de sentido (GARCÍA, 2009). Assim, apesar de reconhecerem a importância dos estudos sobre práticas heteroglóssicas, estudiosos alinhados ao construto transglossia sugerem a adoção do prefixo "trans", por ele capturar melhor as práticas nas quais estão interessados.

Nas palavras de Dovchin, Pennycook e Sultana (2018), o paradigma transglóssico reúne orientações "trans" da linguagem, quais sejam a translinguística, a transmodalidade e a transtextualidade, como forma de ir além da noção de multilinguismo como o soma de línguas separadas e de dar espaço para uma investigação que problematize os impactos da globalização nas práticas de linguagem contemporâneas. A seguir, eu teço comentários sobre cada uma dessas orientações.
Numa perspectiva translinguística, espera-se que a análise das práticas comunicativas enfoque não na língua como um código separado, mas como um recurso que ganha sentido tanto espacial como temporalmente, a partir de seus elementos históricos e locais. Já o conceito da transmodalidade é utilizado como uma crítica ao construto da multimodalidade, uma vez que para Dovchin (2020), de forma similar ao paradigma do multilinguismo, que tende a pluralizar o monolinguismo ao invés de problematizá-lo, a multimodalidade reforça o uso da pluralidade dos modos quando poderia se centrar no potencial transgressivo deles. Partindo desse entendimento, pesquisadores envolvidos na análise da comunicação digital começaram a voltar a atenção para as formas em que os processos de construção de sentido na Internet ocorrem para além dos modos semióticos, transgredindo crenças já cristalizadas sobre o lugar da língua e de outras semioses nesses cenários (PENNYCOOK, 2007), por isso a escolha pelo termo transmodalidade. Quanto à transtextualidade, os autores propõem categorias de análise que possam, dentre outros aspectos, acentuar as relações sócio históricas da construção do texto, apontar para as referências indexicais inferidas no embate entre vozes e ideologias e permitir aos sujeitos lançar mão da sua própria interpretação sobre as suas práticas de linguagem.

Portanto, a partir da transglossia, espera-se que o trabalho com as práticas translíngues possa ser voltado para a natureza transgressiva (ao invés da mera celebração da heterogeneidade e multiplicidade) dos recursos semióticos. Dessa forma, como postulam Dovchin, Pennycook e Sultana (2018, p. 35): 
[...] O paradigma transglóssico nos permite revelar as vozes dentro de uma voz e os processos através dos quais os indivíduos usam as vozes para refletir suas ideias pessoais, sociais e históricas em relação às ideias contraditórias e conflitantes dos outros [...].

Um dos ambientes mais profícuos para o acesso às práticas hetero/transglóssicas de sujeitos translíngues ${ }^{5}$ é aquele moldado pelos espaços digitais. Sob esse viés, tem crescido o número de pesquisas centradas não no papel do meio (computador) na comunicação digital, mas sim no questionamento da ingênua percepção da Internet como um espaço democrático e igualitário, em que os sujeitos podem ser quem eles quiserem. Em oposição a essa postura, pesquisas têm assumido a ideia de que os processos de comunicação online são multifacetados e interligados às identidades offline dos sujeitos de formas complexas (ANDROUTSOPOULOS, 2006). Com isso, a distinção entre on e offline se torna improdutiva, quando o que deveria interessar, na verdade, seria a investigação das maneiras através das quais os sujeitos mobilizam recursos semióticos para construir sentido, afirmar, negar, questionar e transformar suas relações com os significados alcançados.

Os estudos sobre construção identitária e o Facebook não seguiram caminhos diferentes. Apesar de grande parte deles ter sido encabeçada por áreas da Comunicação e Sociologia, por exemplo, pesquisas (socio) linguísticas sobre identidade e redes sociais têm crescido, refletindo um interesse pela linguagem em espaços outros. 0 que esse crescimento também indica é o interesse pelo

5 Apresentadas as considerações teóricas sobre o tema e buscando fazer jus à orientação que tenho defendido neste artigo, passarei a caracterizar os sujeitos, antes chamados de bi/multilíngues, de translíngues. Essa é uma tentativa de deslocar o foco nas "línguas" para os sujeitos como centro das práticas comunicativas. entendimento de que não só a linguagem é o elemento chave a partir do qual os sujeitos performam e constroem suas identidades, mas também que é através da combinação e transformação de práticas transmodais que novos atos de identidade são iniciados.

Para Bolander (2017), o Facebook oferece uma variada gama de recursos para que os sujeitos negociem/construam suas identidades. Segundo a autora, esses elementos só ratificam o entendimento de identidade como um processo, em que, continuamente, seus usuários relacionam suas práticas com suas vidas offline. Para Bolander (2017, p. 146 , grifos meus)

[...] Esse processo se inicia quando um usuário/a faz uma conta no Facebook e é impulsionado/a a completar informações sobre si mesmo/a, por exemplo, sua data de nascimento, seu estado civil, trabalho e escolaridade e hobbies. Grande parte dessas informações é oferecida através da linguagem escrita, por exemplo, através do ato de escrever textos curtos sobre sua visão política e religiosa, através da prática de copiar e colar links em páginas de grupos ou na própria página pessoal ou escolher, de uma lista de respostas pré-determinadas, opções referentes ao status de relacionamento - 'casado', 'solteiro', 'noivo' etc.

Além desses aspectos que indicam traços identitários dos sujeitos que usam redes sociais como o Facebook, tem sido de interesse de pesquisadores (inclusive o meu), saber como essas plataformas proporcionam encontros translíngues antes nunca visto, produzindo, assim, novas práticas de linguagem. Nesse contexto, o foco recai sobre os processos em que os sujeitos negociam os diversos recursos semióticos que compõem seus repertórios comunicativos como forma de construir suas identidades.

Tendo isso em mente, os usuários do $\mathrm{Fa}$ cebook muitas vezes negociam a opção de 
recursos semióticos, incluindo as línguas que compõem os seus repertórios, levando em conta o tipo de identidade que desejam performar para o seu público. Essa opção de recursos está, assim, estritamente relacionada ao grau em que os sujeitos pretendem se projetar como membros globais ou locais na rede social. Por isso que a negociação entre línguas e identidades globais e locais é entendida por Barton e Lee (2015) em termos de glocalização. Para os autores, participar como uma pessoa glocal é uma maneira que os usuários de redes sociais têm para maximizar a acessibilidade de seus perfis, onde explicam sua cultural local para o mundo. Assim, “[...] escrever de modo multilíngue é umas das práticas de letramento essenciais, em que as pessoas projetam identidades glocais online [...]" (BARTON; LEE, 2015, p. 113).

Após contextualizar os construtos que embasam o estudo empreendido neste artigo, eu apresento, na sequência, a natureza da pesquisa e discuto suas particularidades e possibilidades para a análise de práticas translíngues no Facebook. Também contextualizo o processo de desenvolvimento da pesquisa e apresento os sujeitos envolvidos nela. Por fim, eu explico os instrumentos de geração de dados utilizados e sigo para a análise do post selecionado para este estudo, me fundamentando nos princípios do arcabouço transglóssico juntamente com os pressupostos da noção heteroglóssica de linguagem explorados anteriormente.

\section{Percurso metodológico}

A pesquisa que serve de base para este artigo se insere na abordagem netnográfica, que é uma forma de pesquisa apropriada à investigação dos sentidos culturais construídos pelos sujeitos através da comunicação mediada pelo uso da tecnologia (KOZINETS, 2010). Sua gênese está ligada aos estudos etnográficos, mas voltada à interação online, demandando, portanto, novas formas de se investigar as práticas de linguagem dos nossos dias.

Como parte da pesquisa netnográfica, eu tenho assumido o papel de observador participante, pois tenho construído vínculos com os sujeitos, que vão além da mera relação pesquisador-pesquisado. Nesse contexto, eu tenho acesso as suas práticas de uso da rede social, já eles fazem parte da minha "comunidade de amigos" no Facebook, o que me possibilita não só gerar dados para a análise, como também participar dos textos postados em seus perfis.

Esses dados têm sido levantados a partir da combinação de três instrumentos básicos do trabalho netnográfico: questionários, entrevistas e anotações de campo. Para Kozinets (2010), a geração de dados na netnografia implica a comunicação com os sujeitos, envolvendo, assim, engajamento, contato, interação e colaboração. 0 autor deixa claro, portanto, que os pesquisadores em netnografia estão interagindo não apenas com plataformas digitais, mas sim com pessoas.

O contato estabelecido com os sujeitos foi feito através do próprio Facebook. Como todos os participantes já eram meus "amigos" nessa rede social, eu já tinha acesso aos seus textos antes mesmo de convidá-los para participar da pesquisa. Foi exatamente esse contato com os posts que me levou a desenvolver uma pesquisa de doutorado em que eu pudesse problematizar os processos de construção de sentido em que esse sujeitos translíngues se envolviam através de suas atualizações em seus perfis.

0 convite foi feito via e-mail, através do qual eu também enviei um questionário 
para levantar dados sociolinguísticos dos sujeitos. Após o convite para participar da pesquisa e estando de posse das respostas dos questionários enviados, eu selecionei para análise, textos em que fosse evidente a mescla de recursos linguístico-semióticos. Esses textos foram printados da seção do $F a$ cebook, "No que você está pensando?" e, em seguida, transcritos tais como foram postados. Como tenho lidado com textos em que são empregados variados recursos linguísticos, dos quais não tenho conhecimento, eu tenho obtido ajuda dos próprios sujeitos da pesquisa com a tradução para o inglês, quando necessário. Após a etapa de análise, conduzi entrevistas, via chat do Facebook, para levantamento de esclarecimentos adicionais e para investigar suas motivações por trás do emprego daqueles recursos.

Neste artigo, devido ao seu escopo e limitações de espaço, apresento apenas um post publicado por um dos sujeitos participantes da pesquisa. A esse sujeito foi dado o nome de " 0 ", um homem de 28 anos, natural de Oyo, na Nigéria, onde grande parte da população, assim como ele, se comunica em iorubá, inglês, hausa e pidgin. Até o fechamento da escrita deste texto, ele cursava doutorado nos Estados Unidos. 0 primeiro contato que tive com " $\mathrm{O}$ " foi quando participamos de um programa de intercâmbio de ensino de línguas naquele país em 2015. Desse período em diante, eu tive acesso as suas publicações, que eram dedicadas, em sua maioria, a comentários sobre política, esportes e as suas relações familiares.

0 motivo de " $O$ " e demais participantes terem sido selecionados foi a compatibilidade dos seus perfis socioculturais com os objetivos da pesquisa, cujo foco está nas práti-

6 Respeitando os princípios éticos de pesquisa, foram utilizados pseudônimos para fazer referência aos participantes. cas digitais híbridas de sujeitos nascidos em países que passaram por processos de colonização. Para este artigo, o texto de "O" foi selecionado porque ilustra as discussões aqui empreendidas quanto ao caráter heteroglóssico da linguagem em redes sociais.

\section{Análise e discussão dos dados}

Abro essa seção com o post escrito por " 0 ", porém, para melhor compreendê-lo, é necessário, inicialmente, resgatar as relações transtextuais de sua produção (DOVCHIN; PENNYCOOK; SULTANA, 2018).

0 post foi escrito logo após ataques terroristas na capital da Somália, Mogadíscio, em 14 de outubro de 2017, que deixou mais de 600 mortos. 0 ataque ocorreu após uma série de outros atentados terroristas em cidades europeias, que mobilizou um número considerável de usuários de sites de redes sociais para demonstrar solidariedade às vítimas. Esses atos incluíam, dentre outras coisas, a troca das fotos de perfis pelas bandeiras dos países que sofreram os ataques e o uso da hashtag, \#PrayFor.

No texto, " 0 ” expressa sua insatisfação com a baixa cobertura dos ataques na Somália na mídia, principalmente nos Estados Unidos, onde residia na época, assim como a pouca importância dada pela própria mídia africana. "O" usa a hashtag, \#PrayFor7, de forma bastante irônica, convidando os participantes de sua rede social a refletirem sobre como vidas africanas não teriam o mesmo valor das europeias quando se trata de comoção nas redes sociais.

7 A hashtag, \#PrayFor, em português "Ore/Reze por...", foi usada pela primeira vez na rede social Twitter, em 2011, quando um terremoto atingiu a ilha de Tohoku, no Japão. Ela se tornou popular, no entanto, em 2015, quando o astro pop, Justin Bieber, a usou como forma de prestar solidariedade às vítimas dos ataques terroristas em Paris. 


\begin{tabular}{|c|c|}
\hline TEXTO DO FACEBOOK & TRADUÇÃO \\
\hline $\begin{array}{l}\text { "O”: So, no one is praying for Somalia? } \\
\text { Hahahaha. Not even the Africans that } \\
\text { prayed for Paris, London, Manchester, etc.? } \\
\text { Y'all really need to unfetter your minds. } \\
\text { Why does it even matter? The prayers you } \\
\text { have said in the past weren't answered, } \\
\text { though. Keep praying. }\end{array}$ & $\begin{array}{l}\text { Então, ninguém está rezando pela Somália? } \\
\text { Hahahaha. Nem mesmo os africanos que } \\
\text { rezaram por Paris, Londres, Manchester, } \\
\text { etc.? Vocês realmente precisam abrir as } \\
\text { suas mentes. E por que isso importa? Mas } \\
\text { as preces que vocês fizeram no passado não } \\
\text { foram atendidas. Continuem rezando. }\end{array}$ \\
\hline \multicolumn{2}{|c|}{ COMENTÁRIOS } \\
\hline $\begin{array}{l}\text { "SUJEITO 1": Very little press coverage for } \\
\text { the disaster there. }\end{array}$ & Pouca cobertura do desastre aqui. \\
\hline $\begin{array}{l}\text { “O”: I'm telling you, bro. to them, violene } \\
\text { in Somalia is commonplace. So, why cover } \\
\text { what is inherently Somalian? O ri bakan. } \\
\text { How you dey na? }\end{array}$ & $\begin{array}{l}\text { Estou te dizendo, cara. Para eles, violência } \\
\text { na Somália é algo comum. Então, para que } \\
\text { abordar algo que é inerentemente somali? } 0 \\
\text { que é de alguma forma. Como você está? }\end{array}$ \\
\hline “SUJEITO 1”: “0” Exactly. I dey survive o. & “0” Exatamente. Estou sobrevivendo. \\
\hline $\begin{array}{l}\text { “O”: You na baba na. We don't have a choice } \\
\text { than to survive. }\end{array}$ & $\begin{array}{l}\text { Você é o cara! Não temos outra escolha a } \\
\text { não ser sobreviver. }\end{array}$ \\
\hline
\end{tabular}

O que dizer sobre esse texto, aparentemente comum, escrito por dois jovens comentando um evento numa rede social? Nada fora do ordinário acontece nele. Porém, se adotarmos determinadas perspectivas teóricas, podemos observar que, ao contrário do que parece, esse texto serve de base para discussões de construtos que há tempos vêm configurando foco de interesse nas ciências da linguagem, tais como a Sociolinguística e a LA.

Se analisarmos o post a partir da perspectiva do codeswitching, seríamos orientados a compreender que a presença do que, comumente, conhecemos como "línguas", dá pistas das identidades bi/multilíngues dos seus participantes devido à alternância de recursos associados a "códigos diferentes", dentre eles o inglês (exactly), iorubá $(O$ ri bakan) e pidgin (You na baba na), como marcados em negrito no texto. Nessa tradição, é possível apontar que a influência que as línguas têm umas sobre as outras resulte num caso de interlíngua, tópico recorrente nos estudos sobre aquisição de segunda língua (SELINKER, 1972), ou ainda como um exemplo de interferência (WEINREICH, 1968), termo usado para descrever os desvios das normas nas línguas faladas pelos bilíngues.

Entretanto, a despeito das intensas "alternâncias" demonstradas pelos dois sujeitos que participam da construção do texto ("0" e "Sujeito 1"), pode não ficar claro para que serve cada mudança de recurso linguístico. 0 fato de linguistas terem focado, em demasia, nos sentidos e motivações do codeswitching (GUMPERZ, 1982; MYERS-SCOTTON, 1993) reflete a proposta monolíngue de que a prática não é uma forma de uso natural da linguagem, mas algo que precisaria ser explicado (BAILEY, 2012). Logo, o foco nos recursos linguísticos, oficialmente nomeados como "códigos" ou "línguas", nes- 
se caso, iorubá e inglês e pidgin, pode contribuir para a desconsideração da diversidade da indexicalidade social dentro desses próprios recursos.

Logo, a partir de uma perspectiva translíngue e transglóssica, o que identificamos como recursos de iorubá, inglês e pidgin empregados por "O" e "Sujeito 1" carregam diversas formas semióticas que indexam aspectos de suas experiências identitárias. 0 "inglês", por exemplo, inclui formas ligadas a diversas associações sociais. É possível observar o emprego da norma "padrão" da língua, como pode ser visto em quase todo o post (excluindo-se os comentários), o que demonstra como " $O$ " tem domínio no uso da forma prestigiada da língua inglesa. Podem ser encontradas também formas associadas a grupos mais jovens e diferentes classes sociais, como indexado pelo uso do ( $Y^{\prime} a l l$ ), fazendo com que "O" marque uma posição identitária que o afasta dos mais velhos ou até mesmo o aproxime daqueles que se identificam como afro-americanos, já que tal forma é característica dessa comunidade. Além disso, o próprio fato de os sujeitos transitarem entre recursos linguísticos "distintos" aponta para as suas identidades étnico-linguísticas. É interessante perceber que o texto foi construído, quase em sua totalidade, no que se poderia descrever como "língua inglesa", mas os comentários apresentam uma combinação de "línguas" que só foi possível por conta da interação com o "Sujeito 1", sugerindo que esse compartilhava os mesmos recursos linguístico-semióticos.

Nessa interação, a combinação de "línguas" extrapola a concepção do uso "utilitário" e "funcional" da linguagem, uma vez que os sujeitos lançam mão desses recursos para negociarem sentido localmente. Portanto, o que está em foco aqui é a com- preensão de como os sujeitos buscam alcançar seus objetivos comunicativos (a crítica à mídia e denúncia à inserção de uma possível ideologia "ocidental" na África) mais do que o porquê da "mistura" de seus recursos linguísticos. Não seria produtivo, por exemplo, determinar quando se iniciam ou terminam os recursos de "língua inglesa" quando nos deparamos com "I dey survive o", por exemplo. Se assim o fizéssemos, cairíamos na tentação de apenas tratarmos tal ato de linguagem como um caso de uso de pidgin, o que faria nos associar, assim, a determinadas ideologias linguísticas que atribuem às formas pidgin o status de variedades linguísticas primitivas ${ }^{8}$.

Essa visão do pidgin, entretanto, também é corroborada pelo próprio sujeito. Em entrevista, “ $O$ ” afirma que esse recurso linguístico não pode ser considerado uma língua por ainda não ter atravessado um processo de "normatização". Essa posição indica como o discurso do que pode ou não ser considerado língua está presente no imaginário dos sujeitos, levando-os a assumir posturas que se se aproximam da noção de força centrípeta de Bakhtin (1981), uma vez que o discurso de "normatização" ou "padronização" linguística subjaz a visão de língua como sistema homogêneo e unitário.

Além do exposto, essa é uma breve ilustração de como os sujeitos resistem a determinados discursos através de suas práticas translíngues. A asserção de que "Nós não temos outra escolha a não ser sobreviver" (aqui, o "nós" indica que "O" e "Sujeito 1"

8 De forma geral, "pidgin" e "línguas crioulas" são consideradas formas linguísticas menos complexas desenvolvidas a partir do contato entre variedades não-padrão de uma língua europeia e diversas línguas não-europeias. Para uma compreensão mais ampla e crítica desse debate, sugiro a leitura do linguista congolês, Salikoko Mufwene (2015). 
compartilham um background africano) em língua inglesa e não em pidgin, que fora usado logo anteriormente (You na baba na), sugere que o sentido a ser construído não esteja contido em línguas específicas, mas sim na combinação dos recursos que elas oferecem aos sujeitos. Dessa maneira, eles mobilizam e confrontam diferentes vozes para apontarem suas perspectivas, como nos seguintes exemplos: "O" retoma a popularização do uso da hashtag e denuncia uma possível ausência, no discurso da mídia e dos próprios africanos, da importância de se solidarizar com as vidas na África, enquanto "Sujeito 1" coaduna com as "vozes" de seu "amigo" para assumir uma posição diante do evento. Logo, a multivocalidade dessa prática de linguagem confronta discursos passados e ainda presentes sobre a consideração de vidas não-europeias na mídia, assim como legitima as vozes de sujeitos que se posicionam contra práticas que os marginalizam.

Dentro de uma perspectiva transmodal (DOVCHIN; PENNYCOOK; SULTANA, 2018), é possível perceber que ao empregar diferentes recursos semióticos, "O" dá pistas sobre como os leitores devem interpretar o seu post. No entanto, essa interpretação apresentaria lacunas caso se se buscasse o sentido apenas através da análise dos recursos de língua inglesa usados em seu texto. Como já discutido anteriormente, é possível inferir que a publicação de "O" esteja abordando uma crítica à forma como os ataques terroristas na África (não) são tratados pela mídia "ocidental" e à falta de empatia dos próprios africanos com as vítimas. Entretanto, ao olhar para o texto escrito com recursos de língua inglesa, não é possível perceber o "tom" irônico da publicação. Essa interpretação só é possível quando "língua" e demais recursos são combinados e anali- sados em conjunto. Isso inclui considerar o papel da onomatopeia "Hahahaha" e no emprego do emoji com a língua para fora que é, frequentemente, usado para transmitir humor.

É na combinação nesses recursos que se pode sugerir a ironia no post, pois o emoji no final do texto não desempenha papel acessório na interpretação, pelo contrário, ele transforma o "tom" das palavras, conferindo -as um aspecto de humor, de brincadeira e ironia da mesma forma que a onomatopeia usada para indexar risos. Assim, emoji e onomatopeia contribuem para a construção de sentido conjuntamente com os recursos linguísticos empregados pelo sujeito, que indicam que tanto as palavras como demais recursos virtuais devem ser interpretados holisticamente. Diante disso, é adequado concordar com Pennycook (2007) quando afirma que a perspectiva transmodal desafia as noções de que o sentido reside unicamente nas "línguas" ou que elas são o principal meio de comunicação apesar dos recursos "extralinguísticos" e "para-linguísticos". Dessa forma, Pennycook (2007, p. 50) nos lembra que a "[...] Transmodalidade sugere que não apenas o sentido ocorre em múltiplos modos, ou que a língua não pode ser entendida em isolamento, mas também que não existe nada como língua em isolamento $[\ldots]$..

Outra camada de análise está relacionada ao fato de o texto principal ser escrito com recursos do que conhecemos como "inglês", seja através do uso da norma padrão ou de outras características linguísticas que remetem à língua. Porém, na seção de "comentários" em que interage com "Sujeito 1", “ 0 ” lança mão de outros recursos de seu repertório antes não empregados. Essa manipulação de diferentes recursos linguísticos revela que os participantes de redes sociais 
levam em consideração uma série de fatores ecológicos para o aproveitamento e uso das virtualidades dessas semioses. Nessa direção, Barton e Lee (2015, p. 79) pontuam que "[...] os usuários online sabem muito bem como mobilizar seus recursos linguísticos em diferentes contextos para fins diversos e diferentes pessoas [...]" e apontam para quatro aspectos principais para essa prática, quais sejam, quem é o usuário, qual é o público-alvo, o que postar e como o veículo é utilizado.

Na resposta ao "Sujeito 1", já é possível perceber que o aspecto quem é o público-alvo se torna saliente no manejo do repertório semiótico dos sujeitos. A escrita do texto principal em língua inglesa foi, possivelmente, motivada pela audiência que " $O$ " queria envolver. Essa observação foi confirmada pelo próprio, que, em entrevista conduzida, adicionou o fato de que o uso da língua inglesa nos textos publicados no Facebook leva em consideração o público que ele busca atingir. Dessa forma, o inglês dá mais visibilidade ao seu post e possibilita a participação de sujeitos que não compreendem pidgin e iorubá, por exemplo.

Porém, ao interagir com uma pessoa que tem esses recursos em comum, " 0 " lança mão das possibilidades que essas línguas oferecem para a interação. Esse tipo de prática é denominado de estratégias de resistência por Canagarajah e Dovchin (2019), isto é, os sujeitos decidem sobre o uso de determinadas línguas de acordo o contexto de comunicação para resistir e questionar relações desiguais de poder. Assim, o emprego de línguas tidas como minoritárias na grande rede (iorubá e pidgin) seria uma forma de performar identidades de grupos locais.

Relaciono essa manipulação de línguas às práticas de resistência, uma vez que " 0 " vai na contramão de políticas linguísticas que inferiorizam o pidgin e os seus falantes na Nigéria. 0 seu uso é totalmente desaconselhável nos âmbitos institucionais do país, sendo, inclusive, foco de debates educacionais que buscam desencorajar professores a aceitarem o seu emprego em sala de aula. Com isso, atribui-se ao pidgin o status de "não-língua", indexando características negativas aos seus falantes, por ser considerado um "erro" ou "desvio". Portanto, a utilização do pidgin se constitui como uma estratégia de resistência, uma vez que “ $O$ " se aproveita dos recursos de uma língua falada em sua comunidade que não é necessariamente vista como desejável pelas instituições nigerianas, para criticar seus compatriotas e manifestar sua desaprovação a discursos que menosprezam as vidas africanas.

\section{Discussão final e implicações}

Usar hashtags e alterar as fotos do perfil se tornou a norma e conduta moral a ser seguida na Internet. Tais práticas funcionam como teias que ligam pessoas do mundo inteiro em torno de um objetivo comum. Logo, prestar homenagem em eventos trágicos pode, de certo modo, dar às pessoas uma voz global e, sendo assim, passa a ideia de ser algo possível para todos. Entretanto, apesar da importância das redes sociais nesse contexto, críticos apontam a ineficiência dessas práticas sob o argumento de que mostrar solidariedade através da Internet não é tão eficaz quanto tomar uma atitude efetiva para diminuir os casos de terrorismo, por exemplo. Assim, hashtags e fotos de perfis acabam substituindo ações reais. Adicionado a isso, a crítica quanto à falta de representatividade de outros contextos nesses "atos solidários" aumentou. Ataques terroristas ocorridos em países da África e Ásia, por exemplo, não recebem a mesma 
cobertura e nem indignação dos usuários das redes sociais se comparado ao contexto europeu. Como Hardy (2010) e Said (2004) pontuam, tal fato tem ocorrido por duas razões: primeiro porque a mídia "ocidental" (aqui, diga-se Europa e América do Norte, principalmente) tende a noticiar casos em seus contextos mais próximos, subalternizando histórias e eventos "não-ocidentais"; e, segundo, porque a própria construção social do "outro", aquele "não-ocidental", o diferente de "nós" ainda é muito contraditória e complexa na contemporaneidade.

A afirmação dos autores supracitados é corroborada também pelos próprios usuários das plataformas digitais. Neste artigo, mostrei o caso de " 0 ”, que usou seu espaço na rede social para denunciar uma possível contaminação do discurso midiático europeu em seu continente. Mais interessante ainda foi analisar a forma como esse sujeito empreendeu sua crítica, dando pistas de suas identidades através da combinação de recursos disponíveis tanto pelo seu repertório linguístico-semiótico, bem como pelas ferramentas proporcionadas pela própria Internet.

0 exemplo discutido indica que práticas comunicativas de sujeitos translíngues, como a construída entre " 0 " e "Sujeito 1", indexam determinados conjuntos de valores, ideologias e posições sociais negociadas no aqui e agora da interação. Ao adotar uma perspectiva heteroglóssica na investigação dessas práticas, o mais importante não foi se perguntar quais línguas estavam sendo usadas (apesar de seu lugar na compreensão da natureza da linguagem), mas sim quais recursos eram combinados e desafiados, e para onde eles estavam apontando. Uma perspectiva heteroglóssica, então, me permitiu uma melhor compreensão das tensões e conflitos dentro e por entre os recur- sos que compõem os repertórios dos sujeitos.

\section{Palavras conclusivas}

Neste artigo, eu fiz considerações sobre o papel da visão heteroglóssica de linguagem na análise de práticas translíngues no $F a$ cebook. Tenho consciência de que as limitações de espaço fizeram com que outros aspectos relevantes não fossem abordados de forma mais detalhada e, por esse motivo, ofereci uma breve interpretação dos dados gerados. Finalizo este texto, esclarecendo ainda que, por se tratar de um estudo de natureza netnográfica, a discussão realizada não pode ser generalizada a outros contextos de interações online. Ora, uma vez que o uso da linguagem é extremamente dependente de um conjunto de fatores contextuais, é preciso estar ciente de que qualquer réplica deste estudo em outros grupos está sujeita a novas interpretações e conclusões. No entanto, este artigo pode ser útil como pontapé inicial para o desenvolvimento de investigações, cujo foco recaia na relação entre linguagem e rede social. Por isso, pesquisadores interessados nas discussões aqui apresentadas devem se manter abertos para as possibilidades que a adoção de uma lente transglóssica pode oferecer tanto para a análise de práticas de linguagem em diferentes contextos, quanto na tentativa de expandir nossa compreensão sobre as bases que alicerçam a diversidade social das línguas.

\section{Referências}

ANDROUTSOPOULOS, J. Introduction: Sociolinguistics and computer-mediated communication. Journal of SocioLinguistics, v. 10, n. 4, p. 419-438, 2006.

AUER, P. Bilingual conversation. Amsterdam: John Benjamins, 1984. 
BAILEY, B. Heteroglossia. In: JONES, M. M.; BLACKLEDGE, A.; CREESE, A. The handbook of multilingualism. London: Routledge, 2012, p. 499-507.

BAKHTIN, M. The dialogic imagination: four essays by M. M. Bakhtin. Trad.: Michael Caryl Emerson and Michael Holquist. Austin, TX: Texas University Press, 1981.

BAKHTIN, M. Speech genres and other late essays. Trad.: C. Emerson and M. Holquist. Austin: University of Austin Press, 1986.

BAKHTIN, M. Teoria do romance I: a estilística. Tradução, prefácio, notas e glossário de Paulo Bezerra. São Paulo: Editora 34, 2015.

BLACKLEDGE, A.; CREESE, A. Heteroglossia as practice and pedagogy. In: BLACKLEDGE, A.; CREESE, A. (Org.). Heteroglossia as practice and pedagogy. Dordrecht: Springer, 2014, p. 1-20.

BARTON, D; LEE, C. Linguagem online: textos e práticas digitais. Tradução de Milton Camargo Mota. São Paulo: Parábola, 2015.

BOLANDER, B. Language and identity on Facebook. In: THORNE, S.L.; MAY, S. (Org,). Language, education and technology. Encyclopedia of language and education. Springer International Publishing, 2017, p. 143-153.

CREESE, A.; BLACKLEDGE, A. Translanguaging in the bilingual classroom: a pedagogy for learning and teaching? The modern language journal, v. 94, n. 1, p. 103-115, 2010.

CANAGARAJAH, A. S. Multilingual Writers and the Struggle for Voice in Academic

Discourse. In: PAVLENKO, A.; BLACKLEDGE, A. Negotiation of identities in multilingual contexts. Multilingual Matters LTD., 2004, p. 266289.

CANAGARAJAH, A. S. Transligual Practice: global Englishes and cosmopolitan relations. New York: Routledge, 2013.

CANAGARAJAH, A. S.; DOVCHIN, S. The everyday politics of translingualism as a resistant practice. International journal of multilingualism, v. 16, n. 2, p. 127-144, 2019.

DOVCHIN, S.; PENNYCOOK, A.; SULTANA, S. Popular Culture, Voice and Linguistic Di- versity: young Adults On- and Offline. London: Palgrave Macmillan, 2018.

DOVCHIN, S. Language, social media and ideologies: translingual Englishes, facebook and authenticities. Cham: SpringerBriefs in Linguistics, 2020.

GARCÍA, O. Bilingual education in the 21st century: A Global Perspective. Oxford: Wiley-Blackwell, 2009.

GARCÍA, O.; WEI, L. Translanguaging: language, bilingualism, and education. New York: Palgrave MacMillan, 2014.

GUMPERZ, J.; HYMES, D. (Org.). Code switching in Sociocultural Linguistics. Directions in Sociolinguistics: The Ethnography of Communication. New York: Holt, Rinehart, and Winston, 1972.

GUMPERZ, J. Discourse strategies. Cambridge: Cambridge University Press, 1982.

HARDY, J. Western media systems. London: Routledge, 2010.

HELLER, M. Codeswitching: Anthropological and Sociolinguistic Perspectives. Berlin: Mouton de Gruyter, 1988.

KOZINETS, R. Netnography: doing ethnographic research online. Londres: Sage, 2010.

LUCENA, M. I. P.; HALL, S. C. B. de S. Protagonismo local e crítico no translinguajar de quatro moradoras de Alter do Chão. Letras \& Letras, v. 35, n. especial, p. 344-360, 23 out. 2019.

MAKONI, S.; PENNYCOOK, A. Disinventing and (re)constituting languages. Critical inquiry in language studies, v. 2, n. 3, p. 137-156, 2005.

MIGNOLO, W. Local histories/global designs: coloniality, subaltern knowledges, and border thinking. Princeton, NJ: Princeton University Press, 2000.

MUFWENE, S. S. Pidgin and creole languages. In: WRIGHT, J. D. (Org.). International encyclopedia of the social $\&$ behavioral sciences, 2 . ed. Oxford: Elsevier, 2015, p. 133-145.

MYERS-SCOTTON, C. Social motivations for codeswitching: Evidence from Africa. Oxford: Clarendon Press, 1993.

PENNYCOOK, A. Global Englishes and trans- 
cultural flows. London, New York: Routledge, 2007.

OTSUJI, E.; PENNYCOOK, A. Metrolingualism: language in the city. Oxon, UK: Routledge, 2015.

SAID, E. W. Orientalismo: representações ocidentais do Oriente. Lisboa Livros Cotovia, 2004.
SELINKER, L. Interlanguage. IRAL- International review of Applied Linguistics in language teaching, n. 10, p. 209-231, 1972.

WEINREICH, U. Languages in contact: Findings and problems. The Hague: Mouton, 1968.

Recebido em: 14/05/2020 Aceito em: 15/06/2020 